« The death of Ṭahmaspqolī Xān Qājār according to a contemporary Ragusan source (How to become a renegade, 2) », in : Markus Ritter, Ralph Kauz et Birgitt Hoffmann, éds., Iran und iranisch geprägte Kulturen, Studien zum 65. Geburtstag von Bert G. Fragner. Wiesbaden, Ludwig Reichert Verlag, 2008, p. 54-63.

\title{
Michele Bernardini
}

\section{(2) OpenEdition} Journals

\section{Édition électronique}

URL : http://journals.openedition.org/abstractairanica/39407

DOI : 10.4000/abstractairanica.39407

ISSN : 1961-960X

Éditeur :

CNRS (UMR 7528 Mondes iraniens et indiens), Éditions de l'IFRI

Édition imprimée

Date de publication : 15 mai 2011

ISSN : 0240-8910

\section{Référence électronique}

Michele Bernardini, « «The death of Țahmaspqolī Xān Qājār according to a contemporary Ragusan source (How to become a renegade, 2) », in : Markus Ritter, Ralph Kauz et Birgitt Hoffmann, éds., Iran und iranisch geprägte Kulturen, Studien zum 65. Geburtstag von Bert G. Fragner. Wiesbaden, Ludwig Reichert Verlag, 2008, p. 54-63. », Abstracta Iranica [En ligne], Volume 31 | 2011, document 161, mis en ligne le 11 octobre 2012, consulté le 02 octobre 2020. URL : http://journals.openedition.org/ abstractairanica/39407 ; DOI : https://doi.org/10.4000/abstractairanica.39407 
« The death of Țahmaspqolī Xān Qājār according to a contemporary Ragusan source (How to become a renegade, 2) ", in : Markus Ritter, Ralph Kauz et Birgitt Hoffmann, éds., Iran und iranisch geprägte Kulturen, Studien zum 65. Geburtstag von Bert G. Fragner. Wiesbaden, Ludwig Reichert Verlag, 2008, p. 54-63.

Michele Bernardini

Cet article est consacré à une lettre rédigée par Francesco Crasso (ou Crassi) à Alvise Contarini au sujet de Ṭahmāspqolī Hān, un haut commandant militaire safavide, qui, par une « inexplicable décision », avait en 1635 livré Erevan au sultan Murad IV et était passé ensuite aux Ottomans. Peu de choses sont connues sur Crasso à l'exception du fait que c'était un médecin originaire de Ragouse exerçant auprès de la noblesse ottomane. En Italie il devait avoir une remarquable réputation, car il avait été deux fois sindaco de l'Université de Padoue, renommée pour son enseignement médical. Après une analyse détaillée des rares informations sur la carrière de Crasso, Giorgio Rota décrit son arrivée en 1640 à Constantinople où il travailla avec d'autres docteurs européens, tel le Danois Hans Andreas Skovgaard, lui aussi formé à Padoue. À l'époque du siège de Bagdad par Murad IV, en 1639, Crasso assista le sultan qui était malade à cause de ses 
excès de boisson; le sultan mourut le 8 février 1640 et ce décès eut pour conséquence l'exécution de différents personnages, parmi lesquels Ṭahmāspqolī Hูān. Ensuite, Crasso informa Alvise Contarini de la situation et ce dernier rapporta les derniers développements à Venise; par ailleurs, Contarini avait déjà fourni un avis favorable sur cet informateur, personne de bonne réputation et bien informée des affaires orientales. Le court rapport de Crasso, dont le texte est reproduit dans l'article (p.63), décrit notamment l'exécution par traitrise de l'Emir Ghiondi (Ṭahmāspqolī Hāan) sur l'ordre du Grand Vizir ottoman Kemankeş Kara Mustafa Paşa (1638-1644). Puis, Crasso décrit l'enterrement de Ṭahmaspqoli Hुān derrière l'Arsenal à Constantinople, qui eut lieu sans aucune cérémonie du fait que celui-ci était «hérétique », c'est-à-dire chiite ou plutôt renégat, et peut-être du fait de son désir de retourner en Perse. Pour souligner la crainte que pouvaient avoir les Ottomans de certaines personnalités, le rapport énumère les meurtres précédant cette exécution sommaire, notamment ceux de Beyktāš Hāan (Halef Han Bektasc Han), du tofangčīāqāsī Amīr Fattāḥ (Miri Fetah) et de ses fils qui étaient prisonniers dans la forteresse de Rumeli Hisar (1641), ainsi que ceux de Kantemir Mirza (Canta emiro), chef des Noghāy de Bucak exécuté à Constantinople (1637), et de l'émir druze FaHroddīn Ma‘n II (Man Oghli, 1635).

INDEX

Thèmes : 4.2.1. Safavides et Qâjârs

\section{AUTEURS}

MICHELE BERNARDINI

Università di Napoli « L'Orientale » 